\title{
Albendazole exerts antiproliferative effects on prostate cancer cells by inducing reactive oxygen species generation
}

\author{
UKJIN KIM $^{1}$, CHANGSOO SHIN ${ }^{2}$, C-YOON KIM ${ }^{3}$, \\ BOKYEONG RYU ${ }^{1}$, JIN KIM ${ }^{1}$, JUNPIL BANG ${ }^{1}$ and JAE-HAK PARK ${ }^{1}$ \\ ${ }^{1}$ Department of Laboratory Animal Medicine, Research Institute for Veterinary Science, \\ BK21 PLUS Program for Creative Veterinary Science Research, College of Veterinary Medicine; \\ ${ }^{2}$ Department of Energy Resources Engineering, Seoul National University, Seoul 08826; ${ }^{3}$ Department of \\ Stem Cell Biology, School of Medicine, Konkuk University, Seoul 05029, Republic of Korea
}

Received July 3, 2020; Accepted February 8, 2021

DOI: $10.3892 / \mathrm{ol} .2021 .12656$

\begin{abstract}
Benzimidazole derivatives are used for their antihelmintic properties, but have also been reported to exert anticancer effects. In the present study, the anticancer effects of albendazole on prostate cancer cells were assessed using proliferation, clonogenic and migration assays. To investigate the anticancer mechanisms of albendazole, reactive oxygen species (ROS) levels were measured, and the expression of genes associated with oxidative stress and $\mathrm{Wnt} / \beta$-catenin signaling was confirmed by reverse transcription-quantitative PCR and western blotting. Albendazole selectively inhibited the proliferation of the PC3, DU145, LNCaP and AT2 prostate cancer cell lines at concentrations that did not affect the proliferation of a normal prostate cell line (RWPE-1). Albendazole also inhibited the colony formation and migration of PC3 and DU145 cells, as well as inducing ROS production. Diphenyleneiodonium chloride, an inhibitor of NADPH oxidase (NOX), one of the sources of ROS, decreased basal ROS levels in the PC3 and DU145 cells, but did not reduce albendazole-associated ROS production, suggesting that ROS production following albendazole treatment was NOX-independent. The anticancer effect was decreased when albendazole-induced ROS was reduced by treatment with antioxidants (glutathione and $\mathrm{N}$-acetylcysteine). Furthermore, albendazole decreased the mRNA expression of CDGSH iron sulfur domain 2 , which regulates antioxidant activity against ROS, as well as the antioxidant enzymes catalase, and
\end{abstract}

Correspondence to: Professor Jae-Hak Park, Department of Laboratory Animal Medicine, Research Institute for Veterinary Science, BK21 PLUS Program for Creative Veterinary Science Research, College of Veterinary Medicine, Seoul National University, Building 85, 1 Gwanak-ro, Gwanak, Seoul 08826, Republic of Korea

E-mail: pjhak@snu.ac.kr

Key words: albendazole, prostate cancer, reactive oxygen species, $\mathrm{Wnt} / \beta$-catenin, antiproliferative glutathione peroxidase 1 and 3. Albendazole also decreased the mRNA expression of catenin $\beta 1$ and transcription factor 4 , which regulate $\mathrm{Wnt} / \beta$-catenin signaling and its associated targets, Twist family BHLH transcription factor 1 and BCL2. The albendazole-related decrease in the expression levels of oxidative stress-related genes and $\mathrm{Wnt} / \beta$-catenin signaling proteins was thought to be associated with ROS production. These results suggest that the antihelmintic drug, albendazole, has inhibitory effects against prostate cancer cells in vitro. Therefore, albendazole may potentially be used as a novel anticancer agent for prostate cancer.

\section{Introduction}

The prostate gland is the major accessory organ of the male reproductive system. Prostate cancer is the most frequently diagnosed non-skin cancer in men in developed countries, and is one of the leading causes of cancer-related death (1). In 2020, 191,930 men in the United States were expected to be diagnosed with prostate cancer, with an estimated 33,330 deaths from the disease (2). Prostate cancer is a clinically heterogeneous disease with a variable prognosis (3), and as such, early diagnosis, accurate prognostic prediction and successful management are challenging and controversial (4). The incidence of prostate cancer is age-related and several signaling systems, including the generation of reactive oxygen species (ROS), are known to play an important role in the development and progression of prostate cancer (5).

ROS consist of superoxide anion $\left(\mathrm{O}^{-}\right)$and hydroxyl radicals $(\mathrm{OH})$, as well as non-radical molecules such as hydrogen peroxide $\left(\mathrm{H}_{2} \mathrm{O}_{2}\right)(6)$. ROS are primarily produced by mitochondrial respiratory chain enzymes, including NADPH oxidase (NOX), xanthine oxidase and nitric oxide synthase, as well as arachidonic acid oxidation and metabolic enzymes such as cytochrome P450s, lipoxygenase and cyclooxygenase (7). Low or moderate levels of ROS act as signaling molecules for cellular proliferation, differentiation and stress-responsive survival pathways (8). However, high ROS levels can induce cell cycle arrest, apoptosis and necrosis (9).

Benzimidazole derivatives (BZMs) are used as anthelmintic drugs, but BZMs such as albendazole, flubendazole and 
mebendazole have also been repurposed for their anticancer effects (10-12). Albendazole is a broad-spectrum anti-parasitic drug (13) with low toxicity, which inhibits glycolytic metabolism in the parasite, resulting in death $(14,15)$. Albendazole has also been reported to inhibit cancer cell glycolysis (16), induce cell cycle arrest (17), and downregulate vascular endothelial growth factor receptor and hypoxia inducible factor 1A expression $(18,19)$. A recent study demonstrated that albendazole induces leukemia cell apoptosis by increasing ROS production in a non-mitotic manner (20). Albendazole has also been reported to inhibit the development of hepatocellular carcinoma (21), as well as that of colorectal (22), ovarian (23), lung (16), breast (24), gastric (25) and head and neck (26) cancer. Although albendazole inhibits the development of prostate cancer when used in combination with other anticancer agents, the mechanism of these anticancer effects have not been evaluated in detail (27).

In the present study, the anticancer effects of albendazole on prostate cancer cells were investigated, and the results confirmed that ROS play an important role in promoting its anticancer effects. Oxidative stress-related and Wnt signaling genes are downregulated in the presence of ROS. Therefore, albendazole may be used as a novel antitumor agent for prostate cancer.

\section{Materials and methods}

Cell lines and reagents. The PC-3 and DU145 human prostate cancer cell lines were acquired from the American Type Culture Collection, and AT-2 rat prostate cancer cells was obtained from the Korean Cell Line Bank. The non-tumorigenic human prostate epithelial cell line (RWPE-1) was acquired from Dr Won-Woo Lee and the human prostate cancer cell line (LNCaP) was acquired from Dr So Yeong Lee (both of the College of Veterinary Medicine, Seoul National University, Seoul, South Korea). PC-3, DU145, LNCaP and AT-2 cells were cultured in RPMI-1640 medium (Welgene, Inc.) supplemented with $10 \%$ fetal bovine serum and $1 \%$ penicillin/streptomycin (both Gibco; Thermo Fisher Scientific, Inc.). RWPE-1 cells were cultured in keratinocyte serum-free medium supplemented with $50 \mathrm{mg} / \mathrm{l}$ bovine pituitary extract and $5 \mu \mathrm{g} / 1$ epidermal growth factor (Gibco; Thermo Fisher Scientific, Inc.). All cell lines were maintained at $37^{\circ} \mathrm{C}\left(95 \%\right.$ air, $\left.5 \% \mathrm{CO}_{2}\right)$. Albendazole (cat. no. A1943; Tokyo Chemical Industry Co., Ltd.) and diphenyleneiodonium chloride (DPI; Sigma-Aldrich; Merck $\mathrm{KGaA}$ ) were dissolved in dimethyl sulfoxide (DMSO) to a concentration of $10 \mathrm{mM}$ each. The final DMSO concentration in the culture media was $0.1 \%$, and the same final concentration of DMSO was used for the control. Glutathione (GSH; Sigma-Aldrich; Merck KGaA) and N-acetylcysteine (NAC; Sigma-Aldrich; Merck KGaA) were dissolved in distilled water to a concentration of 100 and $75 \mathrm{mM}$, respectively, with the same distilled water as their respective controls.

Cellular viability assay. Cellular proliferative capacity was analyzed using MTT (Sigma-Aldrich; Merck KGaA) based on the ability of living cells to convert tetrazolium salts to formazan. Briefly, cells were seeded into 96-well culture plates at a density of $1.6 \times 10^{4}$ per well in $200 \mu \mathrm{l}$ media. After culturing for $24 \mathrm{~h}$ at $37^{\circ} \mathrm{C}$, the media were replaced with
FBS-free media for $24 \mathrm{~h}$. The cells were then treated with $0.1,0.5,2.5,5$ and $10 \mu \mathrm{M}$ albendazole or the vehicle control (DMSO), and then cultured for a further $24 \mathrm{~h}$. The treatment concentration of albendazole was determined by referring to previous reports $(12,20)$. The media were then replaced with fresh media containing $100 \mu 1$ MTT (diluted to $0.5 \mathrm{mg} / \mathrm{ml}$ in FBS-free medium from a $5 \mathrm{mg} / \mathrm{ml}$ stock solution) and incubated at $37^{\circ} \mathrm{C}$ for $3 \mathrm{~h}$. The supernatant was removed and $100 \mu \mathrm{l}$ DMSO was added to each well to dissolve the formazan crystals. The absorbance was read at $470 \mathrm{~nm}$ using a microplate reader (BioTek Instruments, Inc.), and all treatments were performed in triplicate.

Clonogenic assay. To determine the longer-term effects of albendazole, a clonogenic assay was performed using PC-3 and DU145 cells in the logarithmic growth phase. Briefly, $\sim 1,000$ cells obtained from a sub-confluent cell culture flask were seeded into 6 -well culture plates in $2 \mathrm{ml}$ media per well. After $24 \mathrm{~h}, 0.1$ and $0.5 \mu \mathrm{M}$ albendazole, or the vehicle (DMSO), were added to the culture medium. The cells were allowed to form colonies for 7 days at $37^{\circ} \mathrm{C}$, and were rinsed with fresh medium every 3 days. When discrete and well-defined colonies had formed, the plates were washed with phosphate-buffered saline (PBS), fixed with $100 \%$ methanol for $10 \mathrm{~min}$ at room temperature and stained with hematoxylin for $30 \mathrm{~min}$ at room temperature. The colonies with $>50$ cells were counted using an inverted microscope (IX70; Olympus Corporation). Plating efficiency (PE) is the ratio of the number of colonies to the number of cells seeded. The number of colonies that arise after treatment, expressed in terms of $\mathrm{PE}$, is the surviving fraction. However, PC3 cells exhibited a more scattered pattern, which made it hard to determine the colony number. Therefore, their colony area was measured instead using the 'colony area' plugin feature of ImageJ software (28). The relative colony area was calculated by multiplying the colony area by the colony intensity.

Wound-healing assay. Cell motility was analyzed using an in vitro wound-healing assay. PC-3 and DU145 cells were seeded into a 6-well plate and cultured in RPMI-1640 medium (supplemented with $10 \% \mathrm{FBS}$ and $1 \%$ penicillin/streptomycin) at $37^{\circ} \mathrm{C}\left(95 \%\right.$ air and $\left.5 \% \mathrm{CO}_{2}\right)$ until $\geq 90 \%$ confluent. Prior to the assay, a preliminary experiment was conducted to determine the lowest FBS concentration required for survival and migration in the control group, and 10\% FBS was deemed necessary for survival (29). A wound was then created in the prostate cell monolayers using a sterile pipette tip. Wound closure was monitored using an inverted microscope (IX70; Olympus Corporation) following 24-h exposure to albendazole at concentrations of 0.1 and $0.5 \mu \mathrm{M}$, or the vehicle (DMSO). All treatments were performed in triplicate, and the wound areas were measured using ImageJ software version $1.51 \mathrm{k}$ (National Institutes of Health).

ROS measurement. The generation of intracellular ROS was determined using 2',7'-dichlorofluorescin diacetate (DCFH-DA; Sigma-Aldrich; Merck KGaA), which is converted to fluorescent 2',7'-dichlorofluorescin (DCF) in the presence of peroxides. After exposure to different concentrations of albendazole, $200 \mu \mathrm{M}$ GSH, $300 \mu \mathrm{M}$ NAC and $10 \mu \mathrm{M}$ DPI 
PC3

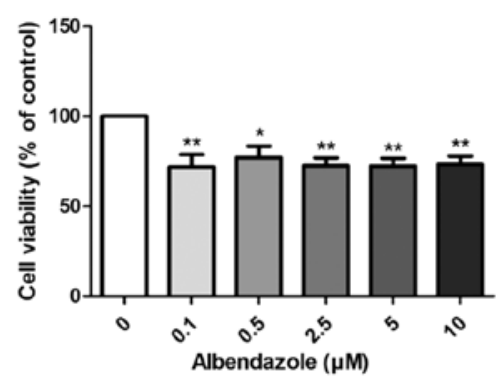

LNCaP

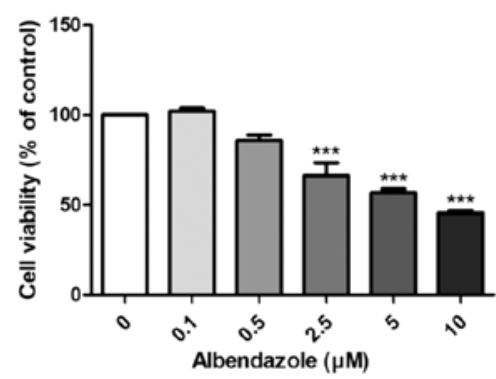

DU145

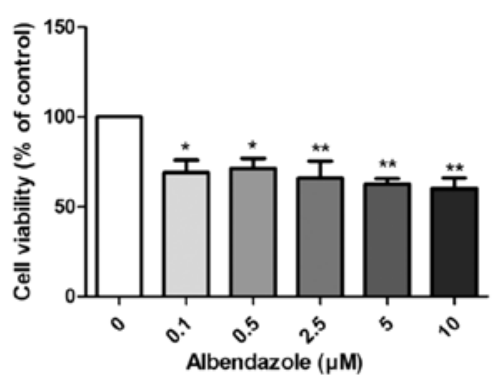

AT2

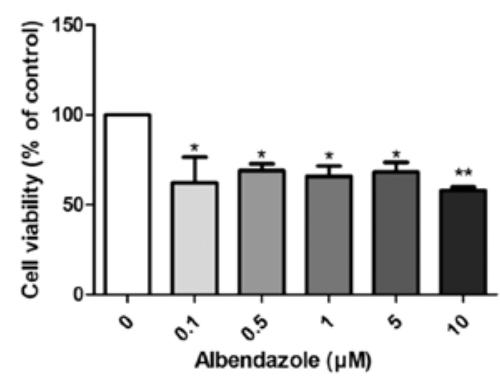

RWPE-1

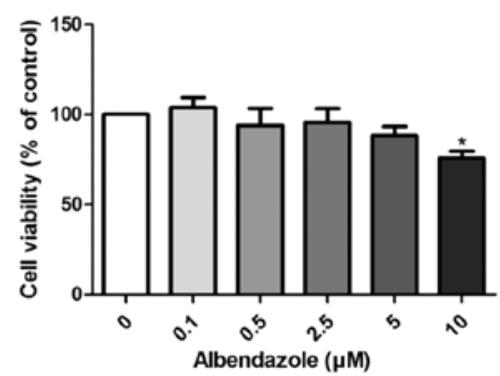

Figure 1. Effect of albendazole treatment on cellular viability. Decreased viability of PC3, DU145, LNCaP, AT2 and RWPE-1 cells following albendazole treatment was confirmed by MTT assay ( $\mathrm{n}=6$ ). In PC3 and DU145 prostate cancer cells, $>0.1 \mu \mathrm{M}$ albendazole decreased viability, while in LNCaP and AT2 cells, $>0.5 \mu \mathrm{M}$ albendazole significantly decreased viability. Decreased viability of RWPE-1, a normal prostate cell line, was observed only at $10 \mu \mathrm{M}$ albendazole. ${ }^{*} \mathrm{P}<0.0,{ }^{* *} \mathrm{P}<0.01$ and ${ }^{* * *} \mathrm{P}<0.001$ vs. $0 \mu \mathrm{M}$ albendazole. Results are presented as the mean $\pm \mathrm{SEM}$.
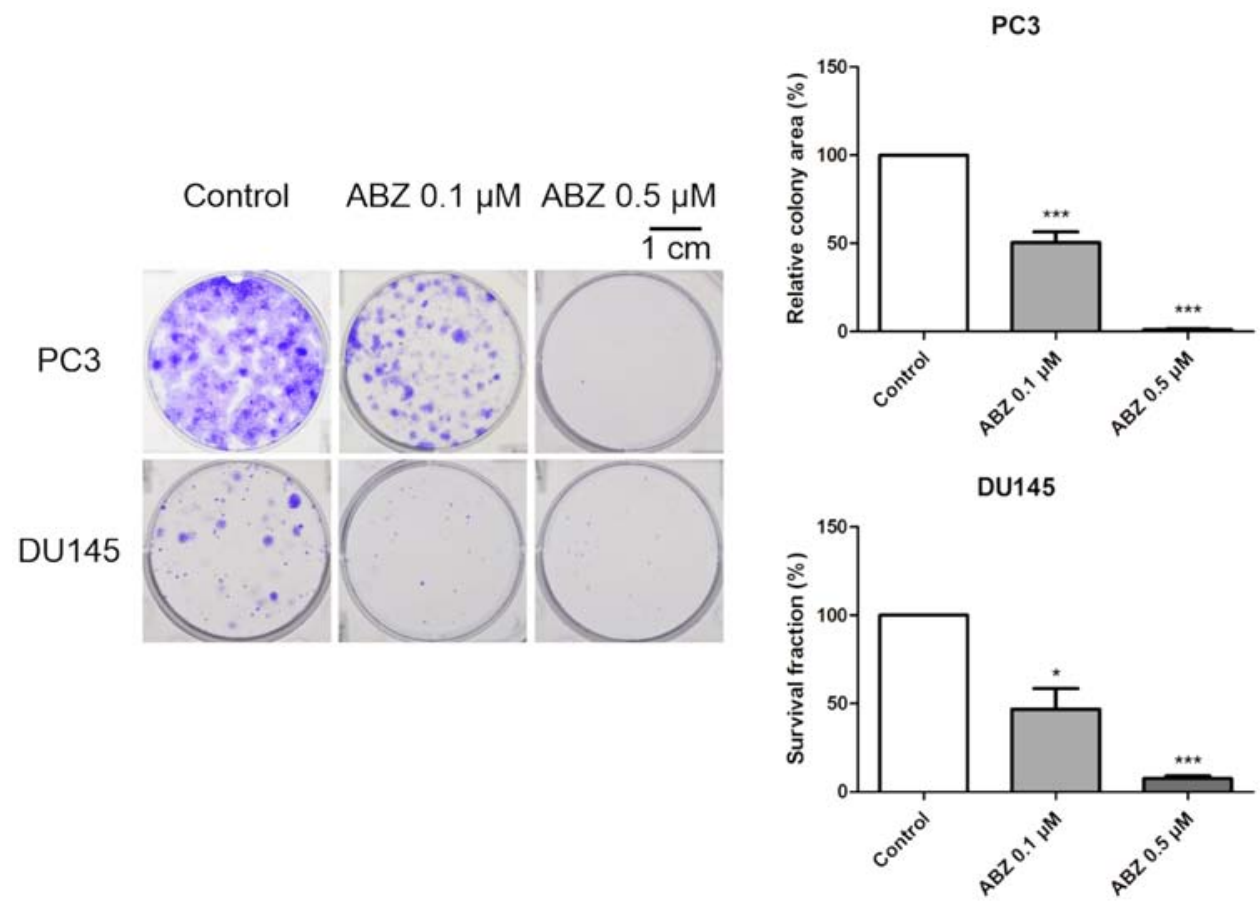

Figure 2. Effects of albendazole treatment on colony formation capacity. To determine the longer-term effects of albendazole treatment, PC3 and DU145 cells were allowed to form colonies for 7 days. PC 3 cells showed a scattered growth pattern, making it difficult to count the colonies. Therefore, the colony area was determined. For DU145 cells, colonies with $\geq 50$ or more cells were counted. PE is the ratio of the number of colonies to the number of cells seeded. The number of colonies that form after drug treatment, expressed in terms of PE, is termed the surviving fraction $(\mathrm{n}=4)$. 0.1 and $0.5 \mu \mathrm{M}$ albendazole decreased the colony formation capacity of PC 3 and DU145 cells in a concentration-dependent manner. ${ }^{*} \mathrm{P}<0.05$ and ${ }^{* * * *} \mathrm{P}<0.001$ vs. control. Results are presented as the mean \pm SEM. PE, plating efficiency; ABZ, albendazole.

simultaneously for $24 \mathrm{~h}, \mathrm{PC}-3$ and DU145 cells were treated with $10 \mu \mathrm{M}$ DCFH-DA for $1 \mathrm{~h}$ at $37^{\circ} \mathrm{C}$, and then washed with PBS. To confirm the association between ROS production by albendazole and NOX, the cells were treated with $10 \mu \mathrm{M}$ DPI, an inhibitor of NOX, in accordance with a previous report (20). The cells were detached using trypsin-EDTA (Gibco; Thermo 

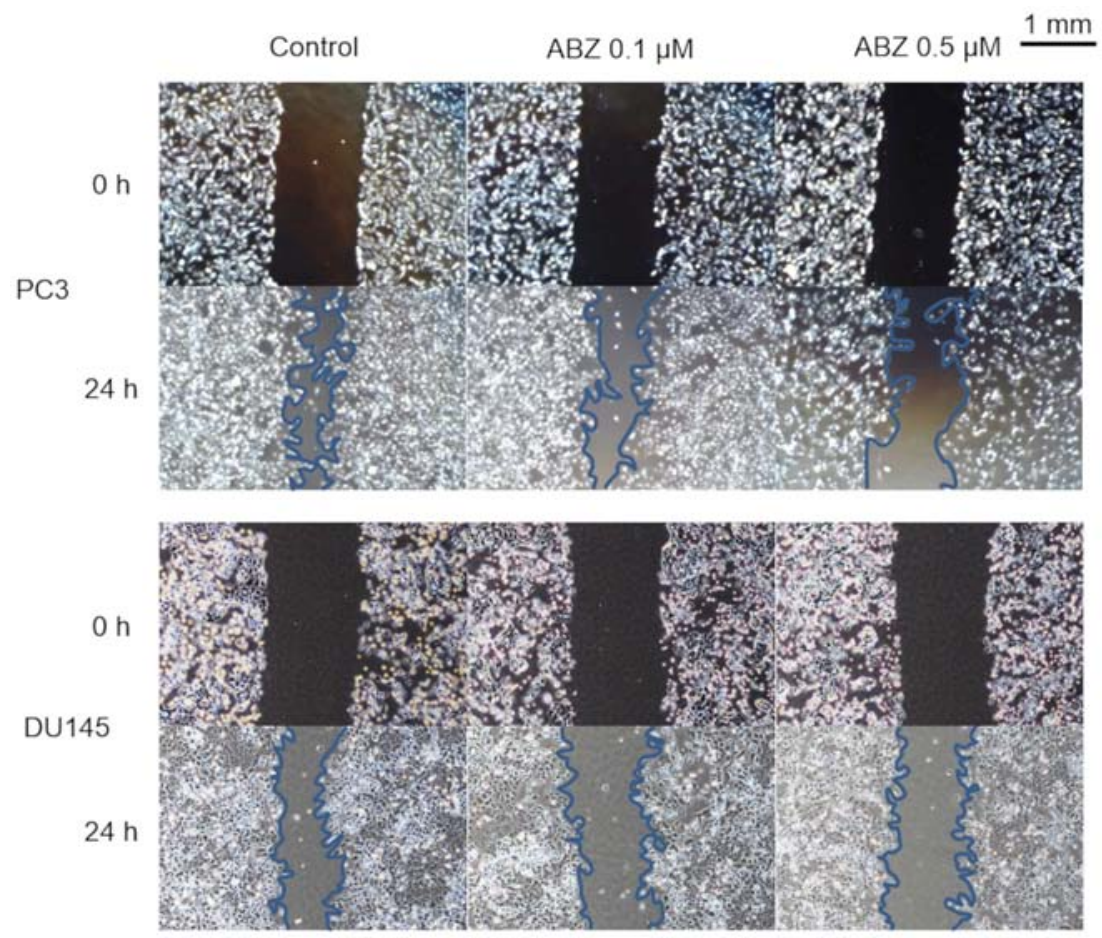

PC3

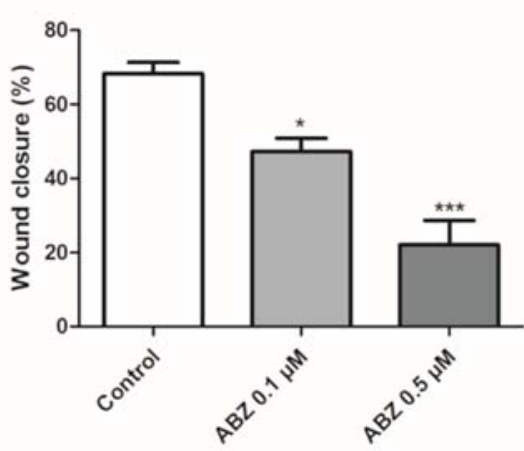

DU145

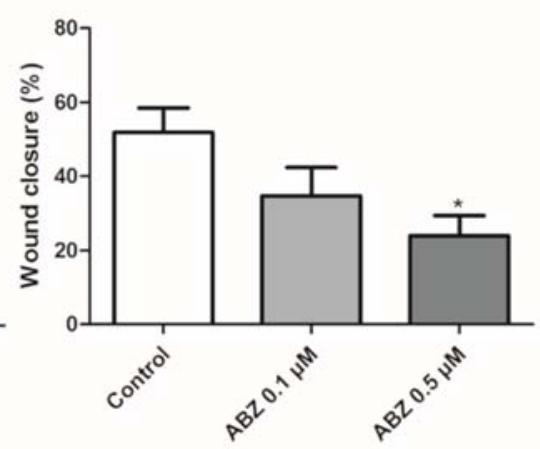

Figure 3. Effects of albendazole treatment on PC3 and DU145 cell migration. Albendazole treatment decreased the migration abilities of PC3 and DU145 cells in a concentration-dependent manner. Magnification, $x 40(n=4)$. ${ }^{*} \mathrm{P}<0.05$ and ${ }^{* * *} \mathrm{P}<0.001$ vs. control. Results are presented as the mean \pm SEM. ABZ, albendazole.

Fisher Scientific, Inc.) and intracellular ROS was detected using a fluorescence spectrometer (Victor 3; PerkinElmer, Inc.) at $485 \mathrm{~nm}$ exposure and $535 \mathrm{~nm}$ emission.

Reverse transcription-quantitative $(R T-q) P C R$. Total RNA was extracted from the cells using a Hybrid-R RNA extraction kit (GeneAll Biotechnology Co., Ltd.), and cDNA was subsequently synthesized using the M-MLV cDNA Synthesis kit (Enzynomics Co., Ltd.) according to the suppliers' instructions. qPCR was performed with the TOPreal ${ }^{\mathrm{TM}}$ qPCR $2 \mathrm{X}$ PreMIX (Enzynomics Co., Ltd.) using a CFX Connect Real-Time PCR Detection system (Bio-Rad Laboratories, Inc.). qPCR was performed with initial denaturation at $95^{\circ} \mathrm{C}$ for $10 \mathrm{~min}$, followed by 35 cycles of denaturation at $95^{\circ} \mathrm{C}$ for $10 \mathrm{sec}$, annealing at $56-66^{\circ} \mathrm{C}$ (depending on the primers) for $15 \mathrm{sec}$ and elongation at $72^{\circ} \mathrm{C}$ for $30 \mathrm{sec}$. The following human gene primers were used for qPCR: Catalase $(C A T)$ forward, 5'-ACAGCAAACCGCACGCTATG-3' and reverse, 5'-CAG
TGGTCAGGACATCAGCTTTC-3'; glutathione peroxidase 1 (GPX1) forward, 5'-CGCTTCCAGACCATTGACATC-3' and reverse, 5'-CGAGGTGGTATTTTCTGTAAGATCA-3'; GPX3 forward, 5'-ACATGCCTACAGGTATGCGT-3' and reverse, 5'-GAGCAGAACAATTGGACCTA-3'; CDGSH iron sulfur domain 2 (CISD2) forward, TTGGCTACCTTGCAGTTC GT-3' and reverse, 5'-ATGTGAACCATCGCAGGCA-3'; hypoxia-inducible factor $1 \alpha(H I F 1 A)$ forward, 5'-GCC AGACGATCATGCAGCTA-3' and reverse, 5'-ATCCAT TGATTGCCCCAGCA-3'; catenin $\beta 1$ (CTNNB1) forward, 5'-ATGACTCGAGCTCAGAGGGT-3' and reverse, 5'-ATT GCACGTGTGGCAAGTTC-3'; twist family BHLH transcription factor 1 (TWIST1) forward, 5'-CTCGGACAAGCTGAG CAAGA-3' and reverse, 5'-GCTCTGGAGGACCTGGTA GA-3'; transcription factor 4 (TCF4) forward, 5'-CCTGGC ACCGTAGGACAAAT-3' and reverse, 5'-TGGGACCATATG GGGAGGG-3'; BCL2 forward, 5'-CTTTGAGTTCGGTGG GGTCA-3' and reverse, 5'-GGGCCGTACAGTTCCACA 


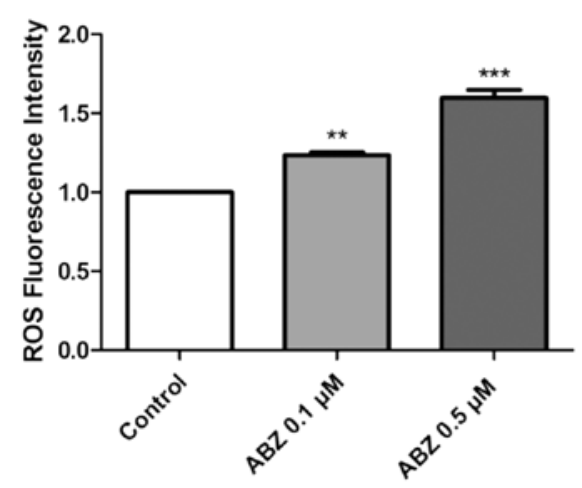

B

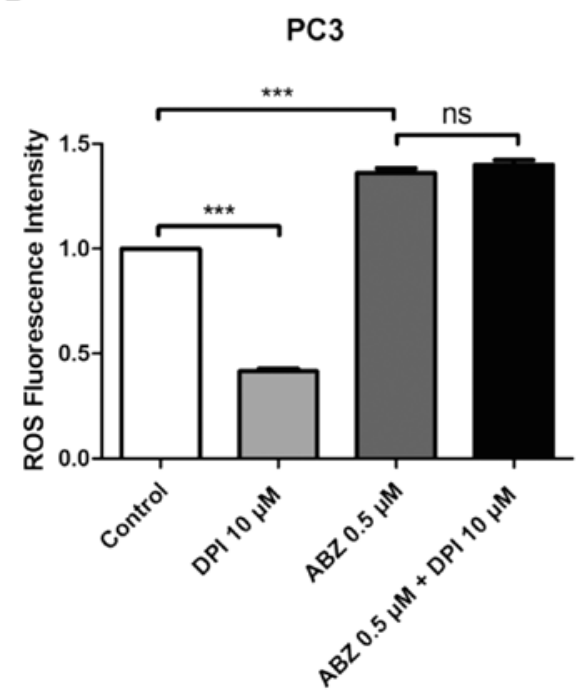

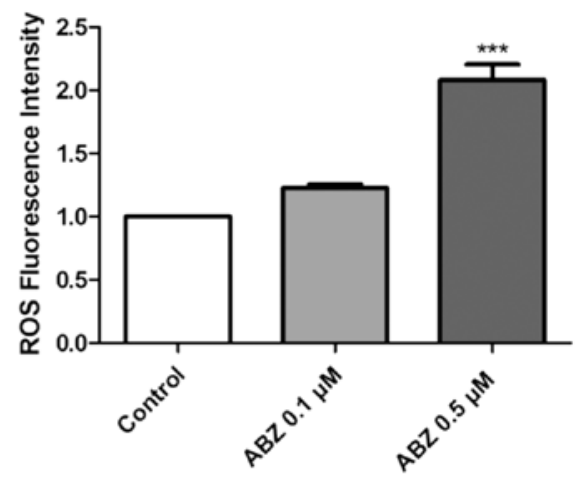

DU145

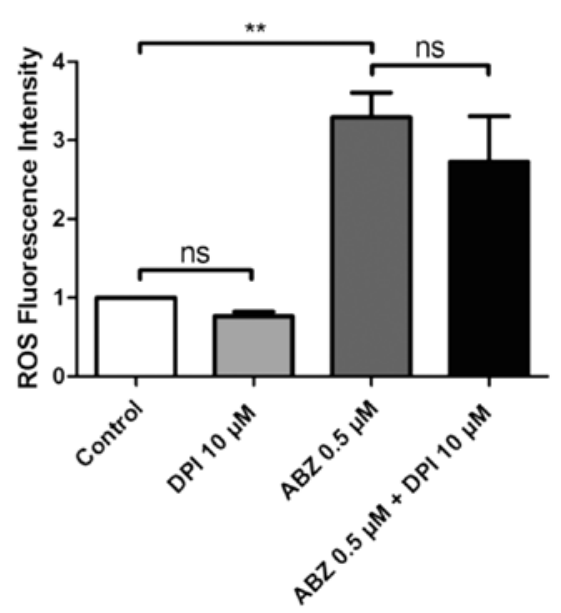

Figure 4. Albendazole treatment increases ROS production in PC3 and DU145 cells. (A) After treating PC3 and DU145 cells with albendazole and incubating with DCFH-DA, ROS levels were measured using a fluorescence spectrometer $(\mathrm{n}=4) .0 .1$ and $0.5 \mu \mathrm{M}$ albendazole increased ROS production in PC 3 and DU145 cells in a concentration-dependent manner. (B) To determine whether NOX influences ROS production, cells were treated with a combination of DPI, a NOX inhibitor, and albendazole. ROS production was assessed by adding DCFH-DA and measuring fluorescence $(n=4)$. DPI alone decreased the basal ROS levels of PC 3 and DU145 cells. However, co-treatment with albendazole did not decrease albendazole-induced ROS production. ${ }^{* * *} \mathrm{P}<0.01$ and ${ }^{* * * *} \mathrm{P}<0.001 \mathrm{vs}$. control, or as indicated. Results are presented as the mean \pm SEM. ROS, reactive oxygen species; NOX, NADPH oxidase; DPI, diphenyleneiodonium chloride; ns, not significant; ABZ, albendazole.

AA-3'; and $A C T B$ forward, 5'-CATGTACGTTGCTATCCA GGC-3' and reverse, 5'-CTCCTTAATGTCACGCACGAT-3'. The ratio of target gene fold-change was normalized to that of $A C T B$ expression using the $2^{-\Delta \Delta \mathrm{Cq}}$ method (30).

Western blot analysis. Cells were lysed using buffer containing $25 \mathrm{mM}$ Tris- $\mathrm{HCl}$ ( $\mathrm{pH} 7.4), 120 \mathrm{mM} \mathrm{NaCl}, 0.5 \%$ NP-40, $4 \mathrm{mM} \mathrm{NaF}, 100 \mu \mathrm{M} \mathrm{Na} \mathrm{VO}_{4}$ and protease inhibitor cocktail (GenDEPOT). The protein concentration in the cell lysates was determined using Bradford protein assay (Bio-Rad Laboratories, Inc.). The cell lysates ( $20 \mu \mathrm{g} /$ lane) were resolved by $15 \%$ SDS-PAGE before transferring the proteins to nitrocellulose membranes. After blocking with 5\% skimmed milk (BD Biosciences) and 1\% sodium azide (PanReac AppliChem; ITW Reagents Division) diluted in PBS-Tween (0.1\% Tween-20) for $1 \mathrm{~h}$ at room temperature, the membranes were incubated with anti-TCF4 (1:1,000; cat. no. 2569s; Cell Signaling Technology, Inc.), anti-BCL2 (1:1,000; cat. no. 15071t; Cell Signaling
Technology, Inc.) and anti $\beta$-actin (1:1,000; cat. no. A5441; Sigma-Aldrich; Merck KGaA) primary antibodies overnight at $4^{\circ} \mathrm{C}$. The blots were then incubated with horseradish peroxidase-conjugated IgG secondary antibodies (1:5,000; cat. nos. 31430 and 31460; Thermo Fisher Scientific, Inc.) for $1 \mathrm{~h}$ at room temperature, and developed using Clarity Western ECL Substrate (Bio-Rad Laboratories, Inc.). The density of each band was quantified with ImageJ software v1.51k (National Institutes of Health) and expressed as fold-change relative to that of the control treated with DMSO.

Statistical analyses. All data are presented as the mean \pm standard error. Experiments were repeated three times. Statistical significance was determined using GraphPad Prism 5 software (GraphPad Software, Inc.). The data were analyzed by one-way ANOVA followed by Dunnett's or Tukey's post hoc test, and $\mathrm{P}<0.05$ was considered to indicate a statistically significant difference. 
A

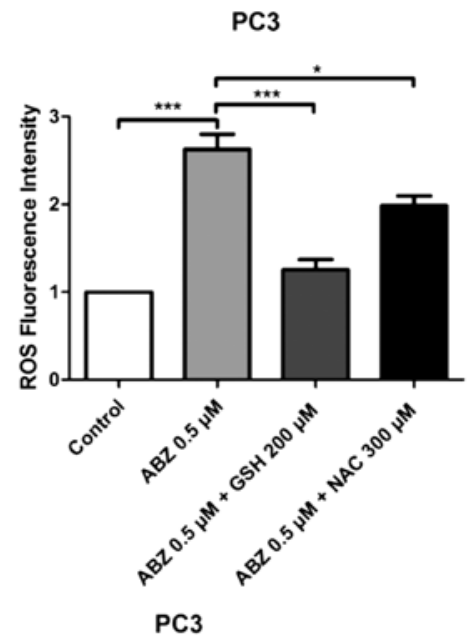

B

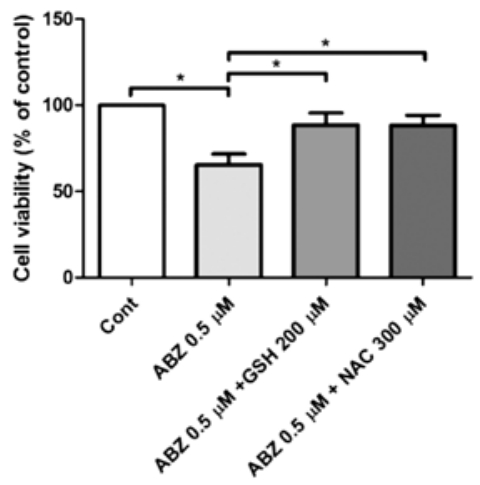

DU145
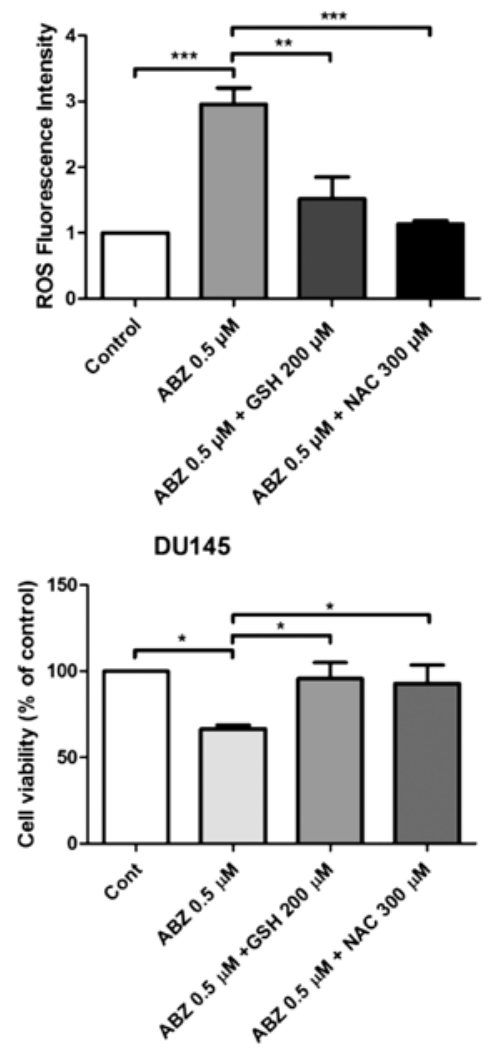

Figure 5. Antioxidants inhibit albendazole-induced ROS production. PC3 and DU145 cells were treated with a combination of albendazole and GSH or NAC. (A) Cellular ROS levels were measured using a fluorescence spectrometer after incubating with DCFH-DA ( $=4)$. Treatment with $0.5 \mu \mathrm{M}$ albendazole increased ROS production in PC3 and D145 cells, while combination treatment with GSH or NAC decreased ROS production. (B) Proliferative potential of PC3 and DU145 cells was assessed using an MTT assay $(\mathrm{n}=6)$. Treatment with $0.5 \mu \mathrm{M}$ albendazole significantly decreased PC3 and D145 cell viability; these effects were offset by treatment with GSH and NAC. ${ }^{*} \mathrm{P}<0.05,{ }^{* *} \mathrm{P}<0.01$ and ${ }^{* * * *} \mathrm{P}<0.001$. Results are presented as the mean \pm SEM. ROS, reactive oxygen species; GSH, glutathione; NAC, N-acetylcysteine; ABZ, albendazole; Cont, control.

\section{Results}

Albendazole decreases the proliferative potential and colony formation capacity of prostate cancer cells. The effects of albendazole on the proliferative and colony formation capacities of prostate cancer cells were investigated. Albendazole reduced the proliferative potential of PC3, DU145 and LNCaP human prostate cancer cells, as well as that of the AT-2 rat prostate cancer cells (Fig. 1). Normal prostate RWPE-1 cells were treated with albendazole as a negative control, which did not affect the proliferative potential at concentrations $<10 \mu \mathrm{M}$. As 0.1 and $0.5 \mu \mathrm{M}$ albendazole reduced the proliferative potential of PC3 and DU145 cells, these concentrations were used for subsequent experimentation. To determine the longer-term effects of albendazole, PC 3 and DU145 cells were treated with albendazole for 7 days. Albendazole inhibited the colony formation capacity of both cell lines, compared with that of the vehicle-treated control cells (Fig. 2).

Albendazole treatment decreases the migration ability of PC3 and DU145 cells. A wound-healing assay was performed to determine the effects of albendazole treatment on the migration of PC 3 and DU145 cells. After $24 \mathrm{~h}$ of treatment with 0.1 and $0.5 \mu \mathrm{M}$ albendazole, the potential for migration of both cell lines was decreased in a concentra- tion-dependent manner compared with that of the control (Fig. 3).

Albendazole promotes ROS production in PC 3 and DU145 cells. ROS production was measured in both PC 3 and DU145 cells $24 \mathrm{~h}$ after albendazole treatment, using the fluorescent dye, DCFH-DA. Compared with the control, albendazole increased intracellular ROS levels in a concentration-dependent manner (Fig. 4A). NOX is the primary source of ROS generation (31). Compared with the control groups, treatment with DPI, a NOX inhibitor, reduced the basal levels of ROS in PC3 and DU145 cells, but only PC3 cells were significantly impacted. However, treatment with DPI did not alter the effects of albendazole on ROS generation in either PC3 or DU145 cells (Fig. 4B). Subsequently, PC3 and DU145 cells were treated with a combination of albendazole and the antioxidants GSH and NAC, to determine whether albendazole-induced ROS levels were associated with its anticancer effects. Indeed, treatment with GSH and NAC decreased albendazole-induced ROS levels (Fig. 5A). Moreover, treatment with GSH and NAC inhibited the antiproliferative effects of albendazole (Fig. 5B).

Albendazole downregulates oxidative stress-related and Wnt/ $\beta$-catenin signaling genes. Treatment with albendazole 

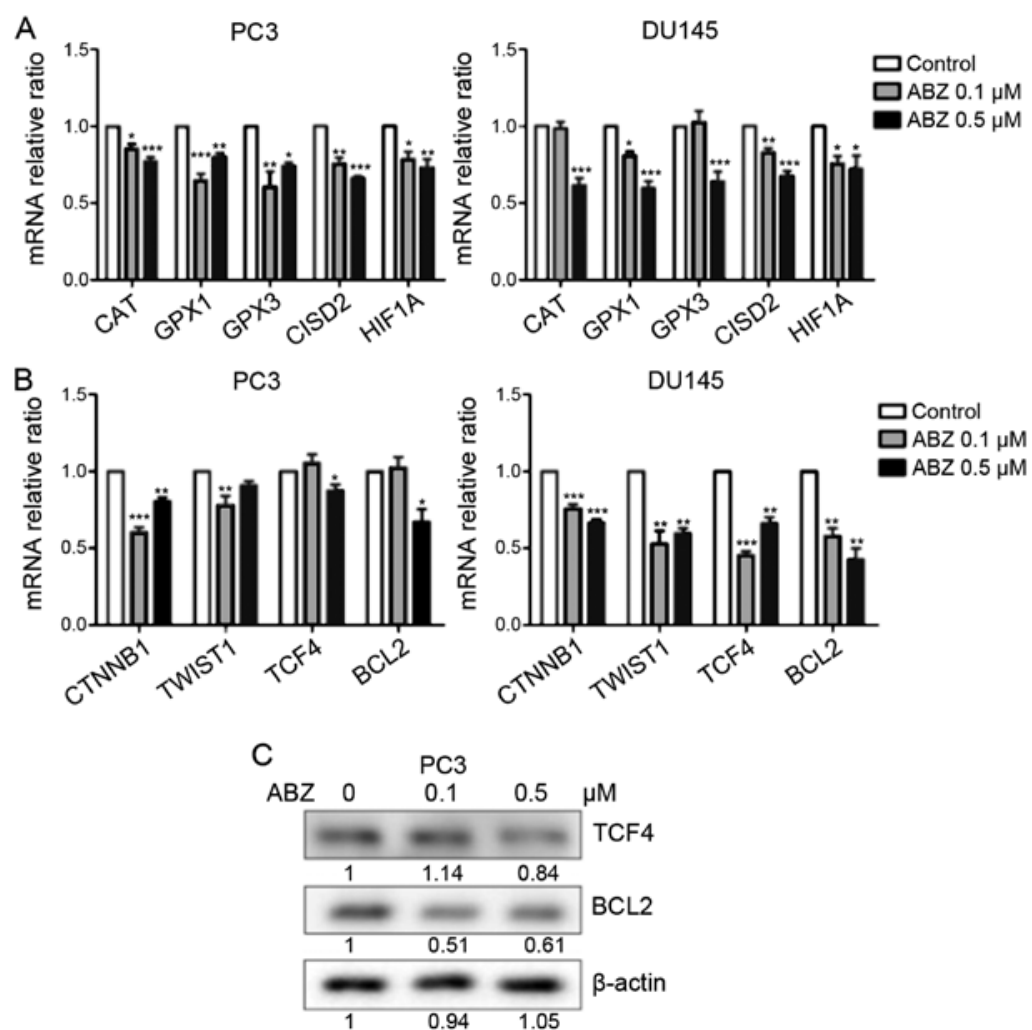

Figure 6. Effects of albendazole treatment on oxidative stress-related and Wnt/ $\beta$-catenin signaling genes in PC3 and DU145 cells. Following treatment with albendazole, gene expression in PC3 and DU145 cells was analyzed by reverse transcription-quantitative PCR and western blotting. (A) mRNA expression levels of the antioxidant enzymes CAT, GPX1, GPX3, CISD and HIF1A were downregulated by albendazole treatment ( $\mathrm{n}=6$ ). (B) The mRNA expression levels of CTNNB1, TWIST1, TCF4 and BCL2 were also downregulated by albendazole treatment $(n=6)$. (C) Albendazole decreased TCF4 and BCL2 protein expression in PC3 cells. ${ }^{*} \mathrm{P}<0.05,{ }^{* *} \mathrm{P}<0.01$ and ${ }^{* * *} \mathrm{P}<0.001$ vs. control. Results are presented as the mean $\pm \mathrm{SEM}$. CAT, catalase; GPX, glutathione peroxidase; CISD2, CDGSH iron sulfur domain 2; HIF1A, hypoxia-inducible factor $1 \alpha$; CTNNB1, catenin $\beta 1$; TWIST1, Twist family BHLH transcription factor 1; TCF4, transcription factor 4; ABZ, albendazole.

increased ROS levels in PC3 and DU145 cells. CAT, GPX1 and GPX3 encode antioxidant enzymes that reduce oxidative stress by catalyzing $\mathrm{H}_{2} \mathrm{O}_{2}$ produced by superoxide dismutase into $\mathrm{H}_{2} \mathrm{O}$ (32). In addition, CISD2 is a redox-sensitive gene that is responsible for increasing the antioxidant capacity of cancer cells against ROS (33). HIF $1 A$ is an important mediator of the hypoxic response, which is also involved in tumor initiation and progression (34). As indicated in Fig. 6A, the mRNA expression levels of CAT, GPX1, GPX3, CISD2 and HIF1A were reduced following albendazole treatment. Furthermore, oxidative stress regulates $\mathrm{Wnt} / \beta$-catenin signaling (35), and albendazole was shown to decrease the mRNA expression of $C T N N B$ and $T C F 4$, genes that regulate $\mathrm{Wnt} / \beta$-catenin signaling $(36,37)$ (Fig. 6B). In DU145 cells, both 0.1 and $0.5 \mu \mathrm{M}$ albendazole decreased the mRNA expression of CTNNB1 and TCF4, whereas in PC3 cells only $0.5 \mu \mathrm{M}$ albendazole decreased the expression of TCF4. The mRNA expression of $C T N N B 1$ decreased at 0.1 and $0.5 \mu \mathrm{M}$ albendazole in PC3 cells. The mRNA expression of BCL2 and TWIST1, targets of Wnt/ $\beta$-catenin signaling $(38,39)$ were also decreased following albendazole treatment in the present study (Fig. 6B). In DU145 cells, 0.1 and $0.5 \mu \mathrm{M}$ albendazole decreased the mRNA expression of BCL2 and TWIST1, whereas in PC3 cells only $0.5 \mu \mathrm{M}$ albendazole decreased the expression of $B C L 2$, and $0.1 \mu \mathrm{M}$ albendazole decreased the expression of TWIST1. Furthermore, albendazole reduced TCF4 and BCL2 protein expression in PC3 cells (Fig. 6C).

\section{Discussion}

Due to the need for effective therapeutic options, the demand for novel anticancer drugs against prostate cancer is increasing. Drug repurposing is emerging as a new strategy to replace existing drug development paradigms, and has been used to discover new anticancer drugs by reusing existing or abandoned compounds approved by the United States Food and Drug Administration (40,41). Albendazole is a safe, well-established antiparasitic agent (13). In the current study, albendazole was demonstrated to suppress the proliferation of PC3, DU145, LNCaP and AT2 prostate cancer cells. Notably, as albendazole did not affect the proliferative potential of normal prostate RWPE-1 cells at concentrations $<10 \mu \mathrm{M}$, the anticancer effect of albendazole appeared to be targeted towards cancer cells.

Furthermore, the anticancer effects of albendazole were also confirmed to be associated with ROS production, as previously reported $(20,42)$. Treating prostate cancer cells with a combination of DPI and albendazole did not affect ROS levels. ROS generation by albendazole-treated prostate cancer cells was thus unrelated to the presence of NOX, a finding which is also consistent with previous reports (20). Antioxidants have been reported to inhibit ROS-induced anticancer effects (43). Thus, in the present study, cells were treated with a combination of albendazole and the antioxidants GSH and NAC. Both of these antioxidants decreased the effects of albendazole on 
prostate cancer cells, suggesting that ROS levels are important for its anticancer effects.

ROS is known to activate and stabilize HIF1A (34), and ROS-induced HIF1A activation is thought to interfere with the anticancer effects of albendazole. However, albendazole-induced HIF1A inhibition has been reported in ovarian and lung cancer $(16,18)$. In the present study, the mRNA expression levels of HIF1A were analyzed, and were significantly reduced by albendazole treatment in PC3 and DU145 cells. As in previous reports $(16,18)$, albendazole was confirmed to decrease the expression of HIF1A in prostate cancer. In addition, HIF1A overexpression has been reported to reduce ROS levels (44). Thus, in the present study, it is highly likely that the decreased expression of HIF IA was involved in albendazole-associated ROS production.

$C A T, G P X 1$ and GPX3 encode antioxidant enzymes that reduce oxidative stress in cancer cells (32). CISD2 expression reduces ROS levels in lung cancer cells and is associated with a poor prognosis in lung adenocarcinoma (33). An increased antioxidant capacity through several mechanisms improves cancer cell survival by increasing the resistance to oxidative stress (45). Albendazole is thought to enhance the anticancer effects of ROS by reducing the expression of these antioxidant enzymes, as well as that of CISD2. Albendazole treatment has also been found to suppress $\mathrm{Wnt} / \beta$-catenin signaling. Tang et al (46) showed that Wnt/ $\beta$-catenin signaling inhibited ROS production in melanocytes. The results of the present study suggested that decreased Wnt/ $\beta$-catenin signaling resulting from albendazole treatment may be associated with increased ROS levels in prostate cancer cells. Albendazole treatment was also found to suppress $\mathrm{Wnt} / \beta$-catenin signaling and decrease the mRNA expression of its target gene, BCL2. An association between the anticancer effects of albendazole and BCL2 has been reported in breast cancer, leukemia and gastric cancer $(25,42,47)$. Therefore, the anticancer effects of albendazole may be associated with the downregulation of $B C L 2$ through the inhibition of $\mathrm{Wnt} / \beta$-catenin signaling.

As primary cultures of malignant prostatic cells have more in vivo physiological characteristics than established cell lines (48), they are considered an appropriate model to verify the anticancer effects of albendazole. However, in the present study, the use of primary cell cultures was considered to be excessively challenging. Therefore, various prostate cancer cell lines were used to verify the anticancer effects of albendazole, including human cell lines (PC3, DU145 and LNCaP) and a rat cell line (AT2). Nonetheless, based on the current data, it is difficult to determine how albendazole may affect prostate cancer metastasis in vivo, or to predict its affects in clinical trials. Prostate cancer has been shown to metastasize to the lungs and lymph nodes in TRAMP mice $(49,50)$, the study of which is a future research consideration, which aims to confirm how albendazole affects the metastasis of prostate cancer in mice. These findings may then be used to highlight the physiological and clinical relevance of albendazole in patients with prostate cancer.

In summary, the results of the present study indicate that albendazole selectively reduced the proliferative potential of prostate cancer cells. The anticancer effect of albendazole was associated with increased ROS levels, which were associated with the downregulation of antioxidant enzymes and the redox-sensitive gene, CISD2. Albendazole also suppressed
Wnt/ $\beta$-catenin signaling. In conclusion, these findings suggest that albendazole may be used as a potential novel anticancer agent for prostate cancer.

\section{Acknowledgements}

Not applicable.

\section{Funding}

The present study was partially supported by the Brain Korea 21 PLUS Program for Creative Veterinary Science Research, Research Institute for Veterinary Science, College of Veterinary Medicine of Seoul National University.

\section{Availability of data and materials}

The datasets used and/or during the current study are available from the corresponding author upon reasonable request

\section{Author's contributions}

JHP and CS conceived and designed the experiments. UK, CYK, BR, JK and JB performed the experiments. UK analyzed the data and wrote the manuscript. JHP and UK confirm the authenticity of all the raw data. All authors read and approved the final manuscript.

\section{Ethics approval and consent to participate}

Not applicable.

\section{Patient consent for publication}

Not applicable.

\section{Competing interests}

The authors declare that they have no competing interests.

\section{References}

1. Torre LA, Bray F, Siegel RL, Ferlay J, Lortet-Tieulent J and Jemal A: Global cancer statistics, 2012. CA Cancer J Clin 65: 87-108, 2015.

2. Siegel RL, Miller KD and Jemal A: Cancer statistics, 2020. CA Cancer J Clin 70: 7-30, 2020.

3. Barbieri CE, Bangma CH, Bjartell A, Catto JW, Culig Z, Grönberg H, Luo J, Visakorpi T and Rubin MA: The mutational landscape of prostate cancer. Eur Urol 64: 567-576, 2013.

4. Cuzick J, Thorat MA, Andriole G, Brawley OW, Brown PH, Culig Z, Eeles RA, Ford LG, Hamdy FC, Holmberg L, et al: Prevention and early detection of prostate cancer. Lancet Oncol 15: e484-e492, 2014.

5. Khandrika L, Kumar B, Koul S, Maroni P and Koul HK: Oxidative stress in prostate cancer. Cancer Lett 282: 125-136, 2009.

6. Wiseman $\mathrm{H}$ and Halliwell B: Damage to DNA by reactive oxygen and nitrogen species: Role in inflammatory disease and progression to cancer. Biochem J 313: 17-29, 1996.

7. Finkel T: Signal transduction by mitochondrial oxidants. J Biol Chem 287: 4434-4440, 2012.

8. Janssen-Heininger YM, Mossman BT, Heintz NH, Forman HJ, Kalyanaraman B, Finkel T, Stamler JS, Rhee SG and van der Vliet A: Redox-based regulation of signal transduction: Principles, pitfalls, and promises. Free Radic Biol Med 45: 1-17, 2008. 
9. Cairns RA, Harris IS and Mak TW: Regulation of cancer cell metabolism. Nat Rev Cancer 11: 85-95, 2011.

10. PantziarkaP,Bouche G,Meheus L, Sukhatme V and Sukhatme VP: Repurposing Drugs in Oncology (ReDO)-mebendazole as an anti-cancer agent. ecancermedicalscience 8: 2014.

11. Armando RG, Mengual Gómez DL and Gomez DE: New drugs are not enough drug repositioning in oncology: An update. Int $\mathrm{J}$ Oncol 56: 651-684, 2020

12. Rushworth LK, Hewit K, Munnings-Tomes S, Somani S, James D, Shanks E, Dufès C, Straube A, Patel R and Leung HY: Repurposing screen identifies mebendazole as a clinical candidate to synergise with docetaxel for prostate cancer treatment. Br J Cancer 122: 517-527, 2020

13. Horton J: Albendazole: A broad spectrum anthelminthic for treatment of individuals and populations. Curr Opin Infect Dis 15: 599-608, 2002.

14. Li QZ, Hao YH, Gao XJ, Gao WX and Bing Z: The target of benzimidazole carbamate against cysticerci cellulosae. Agric Sci China 6: 1009-1017, 2007.

15. Xiao SH, Feng JJ, Guo HF, Jiao PY, Yao MY and Jiao W Effects of mebendazole, albendazole, and praziquantel on fumarate hydratase, pyruvate kinase, and phosphoenolpyruvate carboxykinase of Echinococcus granulosus cyst wall harbored in mice. Zhongguo Yao Li Xue Bao 15: 69-72, 1994.

16. Zhou F, Du J and Wang J: Albendazole inhibits HIF-1 $\alpha$-dependent glycolysis and VEGF expression in non-small cell lung cancer cells. Mol Cell Biochem 428: 171-178, 2017.

17. Pourgholami MH, Cai ZY, Wang L, Badar S, Links M and Morris DL: Inhibition of cell proliferation, vascular endothelial growth factor and tumor growth by albendazole. Cancer Invest 27: 171-177, 2009.

18. Pourgholami MH, Cai ZY, Badar S, Wangoo K, Poruchynsky MS and Morris DL: Potent inhibition of tumoral hypoxia-inducible factor $1 \alpha$ by albendazole. BMC Cancer 10: 143, 2010.

19. Pourgholami MH, Khachigian LM, Fahmy RG, Badar S, Wang L, Chu SW and Morris DL: Albendazole inhibits endothelial cell migration, tube formation, vasopermeability, VEGF receptor-2 expression and suppresses retinal neovascularization in ROP model of angiogenesis. Biochem Biophys Res Commun 397: 729-734, 2010.

20. Wang LJ, Lee YC, Huang CH, Shi YJ, Chen YJ, Pei SN, Chou YW and Chang LS: Non-mitotic effect of albendazole triggers apoptosis of human leukemia cells via SIRT3/ROS/p38 MAPK/TTP axis-mediated TNF- $\alpha$ upregulation. Biochem Pharmacol 162: 154-168, 2019.

21. Pourgholami MH, Woon L, Almajd R, Akhter J, Bowery P and Morris DL: In vitro and in vivo suppression of growth of hepatocellular carcinoma cells by albendazole. Cancer Lett 165: 43-49, 2001.

22. Kang BS, Choi JS, Lee SE, Lee JK, Kim TH, Jang WS, Tunsirikongkon A, Kim JK and Park JS: Enhancing the in vitro anticancer activity of albendazole incorporated into chitosan-coated PLGA nanoparticles. Carbohydr Polym 159: 39-47, 2017.

23. Choi EK, Kim SW, Nam EJ, Paek J, Yim GW, Kang MH and Kim YT: Differential effect of intraperitoneal albendazole and paclitaxel on ascites formation and expression of vascular endothelial growth factor in ovarian cancer cell-bearing athymic nude mice. Reprod Sci 18: 763-771, 2011.

24. Liang J, Li R, He Y, Ling C, Wang Q, Huang Y, Qin J, Lu W and Wang J: A novel tumor-targeting treatment strategy uses energy restriction via co-delivery of albendazole and nanosilver. Nano Res 11: 4507-4523, 2018.

25. Zhang X, Zhao J, Gao X, Pei D and Gao C: Anthelmintic drug albendazole arrests human gastric cancer cells at the mitotic phase and induces apoptosis. Exp Ther Med 13: 595-603, 2017.

26. Ghasemi F, Black M, Vizeacoumar F, Pinto N, Ruicci KM Le CCSH, Lowerison MR, Leong HS, Yoo J, Fung K, et al: Repurposing Albendazole: New potential as a chemotherapeutic agent with preferential activity against HPV-negative head and neck squamous cell cancer. Oncotarget 8: 71512-71519, 2017.

27. Ehteda A, Galettis P, Pillai K and Morris DL: Combination of albendazole and 2-methoxyestradiol significantly improves the survival of HCT-116 tumor-bearing nude mice. BMC Cancer 13: 86, 2013

28. Guzmán C, Bagga M, Kaur A, Westermarck J and Abankwa D: ColonyArea: An ImageJ plugin to automatically quantify colony formation in clonogenic assays. PLoS One 9: e92444, 2014.

29. Liang CC, Park AY and Guan JL: In vitro scratch assay: A convenient and inexpensive method for analysis of cell migration in vitro. Nat Protoc 2: 329-333, 2007.
30. Livak KJ and Schmittgen TD: Analysis of relative gene expression data using real-time quantitative PCR and the $2-\Delta \Delta C T$ method. methods 25: 402-408, 2001.

31. D'Autréaux B and Toledano MB: ROS as signalling molecules: Mechanisms that generate specificity in ROS homeostasis. Nat Rev Mol Cell Biol 8: 813-824, 2007.

32. Marengo B, Nitti M, Furfaro AL, Colla R, Ciucis CD, Marinari UM, Pronzato MA, Traverso N and Domenicotti C: Redox homeostasis and cellular antioxidant systems: Crucial players in cancer growth and therapy. Oxid Med Cell Longev 2016: 6235641, 2016.

33. Li SM, Chen CH, Chen YW, Yen YC, Fang WT, Tsai FY, Chang JL, Shen YY, Huang SF, Chuu CP, et al: Upregulation of CISD2 augments ROS homeostasis and contributes to tumorigenesis and poor prognosis of lung adenocarcinoma. Sci Rep 7: $11893,2017$.

34. Galanis A, Pappa A, Giannakakis A, Lanitis E, Dangaj D and Sandaltzopoulos R: Reactive oxygen species and HIF-1 signalling in cancer. Cancer Lett 266: 12-20, 2008.

35. Korswagen HC: Regulation of the Wnt/ $\beta$-catenin pathway by redox signaling. Dev Cell 10: 687-688, 2006

36. Wang G, Huang Y-X, Zhang R, Hou LD, Liu H, Chen XY, Zhu JS and Zhang J: Toosendanin suppresses oncogenic phenotypes of human gastric carcinoma SGC 7901 cells partly via miR 200a mediated downregulation of $\beta$-catenin pathway. Int J Oncol 51: 1563-1573, 2017

37. Ravindranath A, Yuen HF, Chan KK, Grills C, Fennell DA, Lappin TR and El-Tanani M: Wnt- $\beta$-catenin-Tcf- 4 signallingmodulated invasiveness is dependent on osteopontin expression in breast cancer. Br J Cancer 105: 542-551, 2011.

38. Kypta RM and Waxman J: Wnt/ $\beta$-catenin signalling in prostate cancer. Nat Rev Urol 9: 418-428, 2012

39. Zheng H, Jia L, Liu C-C, Rong Z, Zhong L, Yang L, Chen XF, Fryer JD, Wang X, Zhang YW, et al: TREM2 promotes microglial survival by activating Wnt/ $\beta$-catenin pathway. J Neurosci 37: 1772-1784, 2017

40. Carley DW: Drug repurposing: identify, develop and commercialize new uses for existing or abandoned drugs. Part II. IDrugs 8: 310, 2005

41. Carley DW: Drug repurposing: identify, develop and commercialize new uses for existing or abandoned drugs. Part I. IDrugs 8: 306, 2005.

42. Castro LS, Kviecinski MR, Ourique F, Parisotto EB Grinevicius VM, Correia JF, Wilhelm Filho D and Pedrosa RC: Albendazole as a promising molecule for tumor control. Redox Biol 10: 90-99, 2016.

43. Xiao D, Powolny AA, Moura MB, Kelley EE, Bommareddy A, Kim SH, Hahm ER, Normolle D, Van Houten B and Singh SV: Phenethyl isothiocyanate inhibits oxidative phosphorylation to trigger reactive oxygen species-mediated death of human prostate cancer cells. J Biol Chem 285: 26558-26569, 2010.

44. Sun R, Meng X, Pu Y, Sun F, Man Z, Zhang J, Yin L and Pu Y: Overexpression of HIF-1a could partially protect K562 cells from 1,4-benzoquinone induced toxicity by inhibiting ROS, apoptosis and enhancing glycolysis. Toxicol In Vitro 55: 18-23, 2019.

45. Traverso N, Ricciarelli R, Nitti M, Marengo B, Furfaro AL, Pronzato MA, Marinari UM and Domenicotti C: Role of glutathione in cancer progression and chemoresistance. Oxidative medicine and cellular longevity 2013: 972913, 2013.

46. Tang L, Fang W, Lin J, Li J, Wu W and Xu J: Vitamin D protects human melanocytes against oxidative damage by activation of Wnt/ $\beta$-catenin signaling. Lab Invest 98: 1527-1537, 2018.

47. Khalilzadeh A, Wangoo KT, Morris DL and Pourgholami MH: Epothilone-paclitaxel resistant leukemic cells CEM/dEpoB300 are sensitive to albendazole: Involvement of apoptotic pathways. Biochem Pharmacol 74: 407-414, 2007.

48. Peehl DM: Primary cell cultures as models of prostate cancer development. Endocr Relat Cancer 12: 19-47, 2005.

49. Greenberg NM, DeMayo F, Finegold MJ, Medina D, Tilley WD, Aspinall JO, Cunha GR, Donjacour AA, Matusik RJ and Rosen JM: Prostate cancer in a transgenic mouse. Proc Natl Acad Sci USA 92: 3439-3443, 1995.

50. Gingrich JR, Barrios RJ, Morton RA, Boyce BF, DeMayo FJ, Finegold MJ, Angelopoulou R, Rosen JM and Greenberg NM: Metastatic prostate cancer in a transgenic mouse. Cancer Res 56: 4096-4102, 1996. 